\title{
Synergistic influence of age and serum uric acid on blood pressure among community-dwelling Japanese women
}

\author{
Ryuichi Kawamoto ${ }^{1}$, Yasuharu Tabara ${ }^{2}$, Katsuhiko Kohara ${ }^{3}$, Tomo Kusunoki ${ }^{1}$, Masanori Abe ${ }^{1}$ \\ and Tetsuro Miki ${ }^{3}$
}

Serum uric acid (SUA) levels are strongly correlated with aging, gender, renal function, obesity, and metabolic abnormality; however, whether SUA has a causative role in elevated blood pressure (BP) is still a matter of debate. From a single community, we recruited 1177 eligible women (mean age, $61 \pm 13$ years) during their annual health examination. All subjects were divided into two groups according to their age (participants aged $\geqslant 55$ years and those aged $<55$ years). We investigated whether age and SUA are synergistically associated with BP, independent of confounding factors. Of these subjects, SUA significantly correlated with both systolic BP (SBP; $r=0.236, P<0.001$ ) and diastolic BP (DBP; $r=0.263, P<0.001$ ) in female participants aged $<55$ years but not in those aged $\geqslant 55$ years. The interaction between age and SUA on BP as well as age and body mass index, triglycerides, high-density lipoprotein cholesterol, fasting plasma glucose, prevalence of antidiabetic medication and SUA was a significant and independent determinant of both SBP $(\beta=-0.106, P=0.011)$ and DBP $(\beta=-0.070, P=0.003)$. In participants aged $<55$ years, the multivariate-adjusted odds ratio $(95 \%$ confidence interval) for hypertension was $3.03(1.13-8.11)$ for the highest tertile $\left(4.8-10.8 \mathrm{mg} \mathrm{dl}^{-1}\right)$ of SUA compared with the lowest tertile $\left(0.7-3.8 \mathrm{mg} \mathrm{dl}^{-1}\right)$ but was not significant in those aged $\geqslant 55$ years. These results suggested that age and SUA have a synergistic effect on BP status in community-dwelling women, independent of conventional cardiovascular risk factors. Hypertension Research (2013) 36, 634-638; doi:10.1038/hr.2013.5; published online 28 February 2013

Keywords: age; blood pressure; hypertension; interaction; uric acid

\section{INTRODUCTION}

Hypertension or high blood pressure (BP) is likely the most common disease worldwide and is one of the risk factors for various cardiovascular diseases (CVDs). Moderate elevation of BP leads to shortened life expectancy, and it has been reported that an increased risk of CVD mortality is present in persons with BP levels as low as $115 \mathrm{~mm} \mathrm{Hg}$ systolic BP (SBP) and $75 \mathrm{~mm} \mathrm{Hg}$ diastolic BP (DBP). This risk increases steadily with a rise in BP. ${ }^{1}$ In the guideline of the Seventh Report of the Joint National Committee on Prevention, Detection, Evaluation, and Treatment of High BP (JNC-7) in 2003, individuals with an SBP between 120 and $139 \mathrm{~mm} \mathrm{Hg}$ and/or a DBP between 80 and $89 \mathrm{~mm} \mathrm{Hg}$ were considered as having prehypertension. ${ }^{2}$ Prehypertension frequently progresses to clinical hypertension over several years, especially in older adults, ${ }^{3}$ and is associated with an increased risk of major CVD events, thus lifestyle changes and/or medical treatment are recommended for individuals with prehypertension. ${ }^{1}$

A number of experimental and epidemiological studies have demonstrated that increased serum uric acid (SUA) in humans is also associated with systemic inflammation, ${ }^{4}$ endothelial dysfunction, ${ }^{5}$ hypertension ${ }^{6}$ and CVD morbidity and mortality, $2,7,8$ although the results are not consistent. ${ }^{9}$ SUA levels are strongly correlated with aging, gender, renal function, obesity and metabolic abnormality, and whether SUA has a causative role in elevated BP is still a matter of debate. SUA is more strongly associated with metabolic syndrome in women than in men. ${ }^{10}$ However, there are few reports on the relationship between elevated $\mathrm{BP}$ and the combination of age and UA level in Japanese women.

The aim of this study was to determine whether aging and SUA are synergistically associated with BP by examining cross-sectional data from community-dwelling Japanese women.

\section{MATERIALS AND METHODS}

Subjects

Subjects were selected through a community-based annual check-up process in a rural town located in Ehime prefecture, Japan. Information on medical history, present conditions and drugs was obtained by interviewing the subjects. Other characteristics, such as smoking and alcohol habits, and

${ }^{1}$ Department of Community Medicine, Ehime University Graduate School of Medicine, Ehime, Japan; ${ }^{2}$ Center for Genomic Medicine, Kyoto University Graduate School of Medicine, Sakyo-ku, Kyoto, Japan and ${ }^{3}$ Department of Geriatric Medicine, Ehime University Graduate School of Medicine, Ehime, Japan 
medications, were investigated by individual interviews using a structured questionnaire. Subjects taking medications for hypertension and hyperuricemia were excluded. The final study sample consisted of 1177 eligible persons. The Ethics Committee of Ehime University School of Medicine approved all the procedures, and each subject gave informed consent to participate.

\section{Evaluation of risk factors}

Information on demographic characteristics and risk factors was collected using clinical files. Body mass index (BMI) was calculated by dividing weight (in kilograms) by the square of the height (in meters). We measured BP in the right upper arm of participants in the sedentary position using an automatic oscillometric BP recorder (BP-103i; Colin, Aichi, Japan) while they were seated after having rested for at least $5 \mathrm{~min}$. Appropriate cuff bladder size was determined at each visit based on arm circumference. Normotension

\section{Table 1 Characteristics of female participants categorized by age}

\begin{tabular}{|c|c|c|c|}
\hline Characteristics & Age $<55$ years & Age $\geqslant 55$ years & \\
\hline$N=1177$ & $N=351$ & $N=826$ & $\mathrm{P}$-value ${ }^{a}$ \\
\hline ge (years) & $45 \pm 8$ & $67 \pm 7$ & $<0.001$ \\
\hline dy mass index (B) & 22.7 & 23. & 0.093 \\
\hline$-2, N(\%)$ & $75(21.4)$ & $206(24.9)$ & 0.204 \\
\hline ng status (\%) & $93.2 / 1.7 / 5.1 / 0$ & $98.2 / 0.5 / 1.2 / 0.1$ & $<0.001$ \\
\hline tus $(\%)$ & $41.9 / 47.9 / 10.3$ & $70.7 / 24.9 / 4.4$ & .001 \\
\hline f CVD, $N(\%)$ & $1(0.3)$ & $54(6.5)$ & $<0.001$ \\
\hline $\mathrm{m} \mathrm{Hg})$ & 121 & $137 \pm 21$ & $<0.001$ \\
\hline $\mathrm{m} \mathrm{Hg})$ & $73 \pm 11$ & $79 \pm 11$ & $<0.001$ \\
\hline Triglycerides (mg dl ${ }^{-1}$ ) & $75(55-105)$ & $94(71-128)$ & $<0.001$ \\
\hline HDL cholesterol (mg dl ${ }^{-1}$ ) & $66 \pm 15$ & & 0.008 \\
\hline cholesterol (mo dl-1) & 112 & 127 & $<0.001$ \\
\hline Wering medication & $3(0.9)$ & $60(7.3)$ & $<0.001$ \\
\hline (modl & $88(83-94)$ & $93(88-100)$ & $<0.001$ \\
\hline$N(\%)$ & $5(1.4)$ & $30(3.6)$ & 0.040 \\
\hline eGF & $91.4 \pm$ & $78.5 \pm 16.7$ & $<0.001$ \\
\hline Serum uric acid $\left(\mathrm{mg} \mathrm{dl}^{-1}\right)$ & $4.2 \pm 0.9$ & $4.4 \pm 1.1$ & 0.003 \\
\hline
\end{tabular}

Abbreviations: CVD, cardiovascular disease; DBP, diastolic blood pressure; eGFR, estimated glomerular filtration rate; HDL, high-density lipoprotein; LDL, low-density lipoprotein; $\mathrm{SBP}$, systolic blood pressure.

Data presented as mean \pm s.d. Body mass index was calculated using weight in kilograms divided by the square of the height in meters. Smoking status (never-smoker, past-smoker, light smoker ( $<30$ pack year) and heavy smoker ( $\geqslant 30$ pack year)). Drinking status (non-drinker, occasional drinker $\left(1-6\right.$ days week $\left.^{-1}\right)$ and daily drinker $\left(\geqslant 7\right.$ days week $\left.^{-1}\right)$ ).

eGFR $=194 \times \mathrm{Cr}^{-1.094} \times \mathrm{Age}^{-0.287} \times 0.739$ (if female). Data for triglycerides and fasting plasma glucose were skewed, and are presented as median (interquartile range), and log-transformed for analysis.

a $P$-value: Student's $t$-test for continuous variables or the $\chi^{2}$-test for categorical variables. was defined as SBP $<120 \mathrm{~mm} \mathrm{Hg}$ and DBP $<80 \mathrm{~mm} \mathrm{Hg}$. Prehypertension was defined as SBP of 120-139 $\mathrm{mm} \mathrm{Hg}$ and/or DBP of 80-89 $\mathrm{mm} \mathrm{Hg}$. Hypertension was defined as SBP $\geqslant 140 \mathrm{~mm} \mathrm{Hg}$ and/or DBP $\geqslant 90 \mathrm{~mm} \mathrm{Hg}^{2}$ Cigarette smoking was quantified based on daily consumption and the history of smoking: never-smoker, past-smoker, light smoker $(<30$ pack $\cdot$ year $)$ and heavy smoker $(\geqslant 30$ pack year). Daily alcohol consumption was measured using the Japanese liquor unit in which a unit corresponds to $22.9 \mathrm{~g}$ of ethanol, and the participants were classified into non-drinker, occasional drinkers $\left(<1\right.$ unit dayl $\left.^{-1}\right)$ and daily drinkers $\left(\geqslant 1\right.$ unit day $\left.^{-1}\right)$. Total cholesterol (T-C), triglycerides (TG), high-density lipoprotein cholesterol (HDL-C), fasting plasma glucose (FPG), creatinine (enzymatic method) and SUA were measured during fasting. The low-density lipoprotein cholesterol (LDL-C) concentration was calculated by the Friedewald formula. ${ }^{11}$ Participants with TG levels $\geqslant 400 \mathrm{mg} \mathrm{dl}^{-1}$ were excluded. Estimated glomerular filtration rate (eGFR) was calculated using the following equation: $e G F R=194 \times$ $\mathrm{Cr}^{-1.094} \times$ age $^{-0.287} \times 0.739$ (if female). ${ }^{12}$ Participants with an eGFR $<30 \mathrm{ml} \mathrm{min}^{-1} 1.73 \mathrm{~m}^{-2}$ were excluded.

\section{Statistical analysis}

Statistical analyses were performed using IBM SPSS Statistics Version 20 (Statistical Package for Social Science Japan, Tokyo, Japan). All values are expressed as mean \pm s.d., unless otherwise specified. Data for TG and FPG were skewed and log-transformed for analysis. In the present study, we divided the participants into two groups based on an age of 55 years, which is equivalent to $\geqslant 95 \%$ of age distribution at menopause in a similar investigation. ${ }^{13}$ Differences based on BP status were analyzed by Student's $t$-test for continuous variables or $\chi^{2}$-test for categorical variables. Correlations between SUA and BP were determined using Pearson's correlation test. Multiple linear regression analysis was used to evaluate the contribution of risk factors for SBP or DBP, and analysis of covariance was performed with the use of a general linear model approach to determine the association between age and SUA on BP status. Logistic regression analyses were used to test significant determinants of prehypertension or hypertension status serving as the dichotomous outcome variable. A value of $P<0.05$ was considered significant.

\section{RESULTS}

The characteristics of the study participants categorized by age are illustrated in Table 1. The study sample was 1177 women, aged $61 \pm 13$ (range 19-88) years. SBP, DBP, TG, LDL-C, prevalence

Table 2 Relationship between various characteristics and blood pressure status of female participants categorized by age

\begin{tabular}{|c|c|c|c|c|}
\hline \multirow[b]{4}{*}{ Characteristics $\mathrm{N}=1177$} & \multicolumn{2}{|c|}{$S B P$} & \multicolumn{2}{|c|}{$D B P$} \\
\hline & Age $<55$ years & Age $\geqslant 55$ years & Age $<55$ years & Age $\geqslant 55$ years \\
\hline & $\mathrm{N}=351$ & $\mathrm{~N}=826$ & $\mathrm{~N}=351$ & $\mathrm{~N}=826$ \\
\hline & \multicolumn{4}{|c|}{$r$ (P-value) } \\
\hline Age (years) & $0.317(<0.001)$ & $0.284(<0.001)$ & $0.367(<0.001)$ & $0.107(0.002)$ \\
\hline Body mass index (BMI) $\left(\mathrm{kg} \mathrm{m}^{-2}\right)$ & $0.403(<0.001)$ & $0.137(<0.001)$ & $0.381(<0.001)$ & $0.176(0.001)$ \\
\hline Obesity, $\mathrm{BMI} \geqslant 25 \mathrm{~kg} \mathrm{~m}^{-2}(\%)$ & $0.284(<0.001)$ & $0.123(<0.001)$ & $0.295(<0.001)$ & $0.163(<0.001)$ \\
\hline Smoking status (\%) & $-0.069(0.198)$ & $-0.053(0.130)$ & $-0.108(0.044)$ & $-0.009(0.794)$ \\
\hline Drinking status (\%) & $-0.025(0.641)$ & $-0.131(<0.001)$ & $-0.036(0.505)$ & $-0.042(0.233)$ \\
\hline History of CVD, $N(\%)$ & $0.032(0.550)$ & $0.057(0.099)$ & $0.037(0.488)$ & $0.016(0.637)$ \\
\hline Triglycerides (mg dl-1) & $0.306(<0.001)$ & $0.142(<0.001)$ & $0.303(<0.001)$ & $0.136(<0.001)$ \\
\hline HDL cholesterol (mg dl ${ }^{-1}$ ) & $-0.095(0.076)$ & $0.006(0.865)$ & $-0.070(0.192)$ & $0.001(0.977)$ \\
\hline LDL cholesterol (mg dl-1) & $0.259(<0.001)$ & $-0.030(0.385)$ & $0.348(<0.001)$ & $0.010(0.770)$ \\
\hline Lipid-lowering medication, \% & $0.090(0.091)$ & $0.039(0.264)$ & $0.051(0.345)$ & $0.029(0.408)$ \\
\hline Fasting plasma glucose $\left(\mathrm{mg} \mathrm{dl}{ }^{-1}\right)$ & $0.237(<0.001)$ & $0.154(<0.001)$ & $0.195(<0.001)$ & $0.080(0.022)$ \\
\hline Antidiabetic medication, $N(\%)$ & $0.022(0.686)$ & $-0.033(0.346)$ & $0.006(0.914)$ & $-0.067(0.056)$ \\
\hline eGFR & $-0.112(0.036)$ & $-0.056(0.106)$ & $-0.196(<0.001)$ & $-0.047(0.174)$ \\
\hline Serum uric acid (mg dl ${ }^{-1}$ ) & $0.236(<0.001)$ & $-0.014(0.684)$ & $0.263(<0.001)$ & $0.021(0.554)$ \\
\hline
\end{tabular}

Abbreviations: CVD, cardiovascular disease; DBP, diastolic blood pressure; eGFR, estimated glomerular filtration rate; HDL, high-density lipoprotein; LDL, low-density lipoprotein; SBP, systolic blood pressure.

$r$, Pearson's correlation coefficient.

Data for triglycerides and fasting plasma glucose were skewed and log-transformed for analysis. 
of lipid-lowering medication, FPG, SUA and history of CVD were significantly higher in participants aged $\geqslant 55$ years than in those aged $<55$ years; however, prevalence of smoking and drinking, HDL-C and eGFR were lower. There was no inter-group difference in BMI and prevalence of obesity.

Table 2 shows the relationship between participant characteristics and BP status. Pearson's correlation coefficient showed that SUA as well as age, BMI, prevalence of obesity, TG, LDL-C, FPG and eGFR correlated with both SBP and DBP in participants aged $<55$ years but not in those aged $\geqslant 55$ years.

In addition to their direct associations, we observed a synergistic effect between age and SUA on BP status in Figure 1. In participants aged $<55$ years, SUA was significantly correlated with both SBP $(r=0.236, P<0.001)$ and DBP $(r=0.263, P<0.001)$; however, in those aged $\geqslant 55$ years, SUA was significantly correlated with neither $\operatorname{SBP}(r=-0.014, P=0.684)$ nor DBP $(r=0.021, P=0.554)$. Analysis of covariance showed that the two regression lines in each graph were significantly different $(F=12.78, P<0.001$ and $F=16.92, P<0.001$, respectively).

In Table 3, we assessed the statistical significance of the synergistic relationship using a general linear model with the following confounding factors: age, BMI, smoking status, drinking status, history of CVD, TG, HDL-C, LDL-C, prevalence of lipid-lowering medication, FPG, prevalence of antidiabetic medication, eGFR, SUA and the interaction between age and SUA. The interaction between age and SUA was a significant and independent determinant of both SBP $(\beta=-0.106, P=0.011)$ and DBP $(\beta=-0.070, P=0.003)$.

Table 4 shows the odds ratios (ORs) (95\% confidence intervals (CIs)) of prehypertension and hypertension with higher SUA categories in participants aged $<55$ years and $\geqslant 55$ years. In participants aged $<55$ years, higher SUA categories were positively associated with hypertension. Compared with the lowest tertile $\left(0.7-3.8 \mathrm{mg} \mathrm{dl}^{-1}\right)$ of SUA, the multivariate-adjusted OR (95\% CI) for hypertension was $3.03(1.13-8.11)$ for the highest tertile $\left(4.8-10.8 \mathrm{mg} \mathrm{dl}^{-1}\right)$ but not significant in those aged $\geqslant 55$ years.

\section{DISCUSSION}

In this cross-sectional, population-based study, we have confirmed the prevalence of prehypertension and hypertension, as defined by the JNC-7 criteria, ${ }^{2}$ and their relationship to the SUA levels of female participants categorized by age. This study showed that prehypertension and hypertension are extremely common, affecting more than $33 \%$ and $47 \%$, respectively, of female participants, and higher SUA levels significantly increased with both elevated SBP and DBP in female participants aged $<55$ years but not in those aged $\geqslant 55$ years. Moreover, we observed a synergistic effect between age and SUA on BP status, independent of confounding factors.

The link between hyperuricemia and hypertension has been reported in several studies. Among 9104 participants (54.5\% women, age: 45-64 years) in the Atherosclerosis Risk in Communities study who were free of hypertension at baseline, a higher SUA was associated with a greater risk of hypertension in the overall cohort (hazard ratio (95\% CI) for each s.d. of higher SUA: 1.10 (1.04-1.15) and in the subgroup analyses (black men: 1.32 (1.14-1.54); black women: 1.16 (1.03-1.31); white men: 1.01 (0.94-1.09); white women: $1.04(0.96-1.11)) .^{6}$ In 2520 hypertension-free individuals $(56.3 \%$ women, age: $43-84$ years, $98 \%$ Caucasian) at baseline, multivariable relative risk (95\% CI) of incident hypertension was 1.65 (1.41-1.93) for the highest quartile of SUA $\left(\geqslant 6.56 \mathrm{mg} \mathrm{dl}^{-1}\right)$ compared with the lowest quartile ( $\left.\leqslant 4.37 \mathrm{mg} \mathrm{dl}^{-1}\right) .{ }^{14}$ Among 6036 adolescents aged 12 17 years in the National Health and Nutrition Examination Survey, in
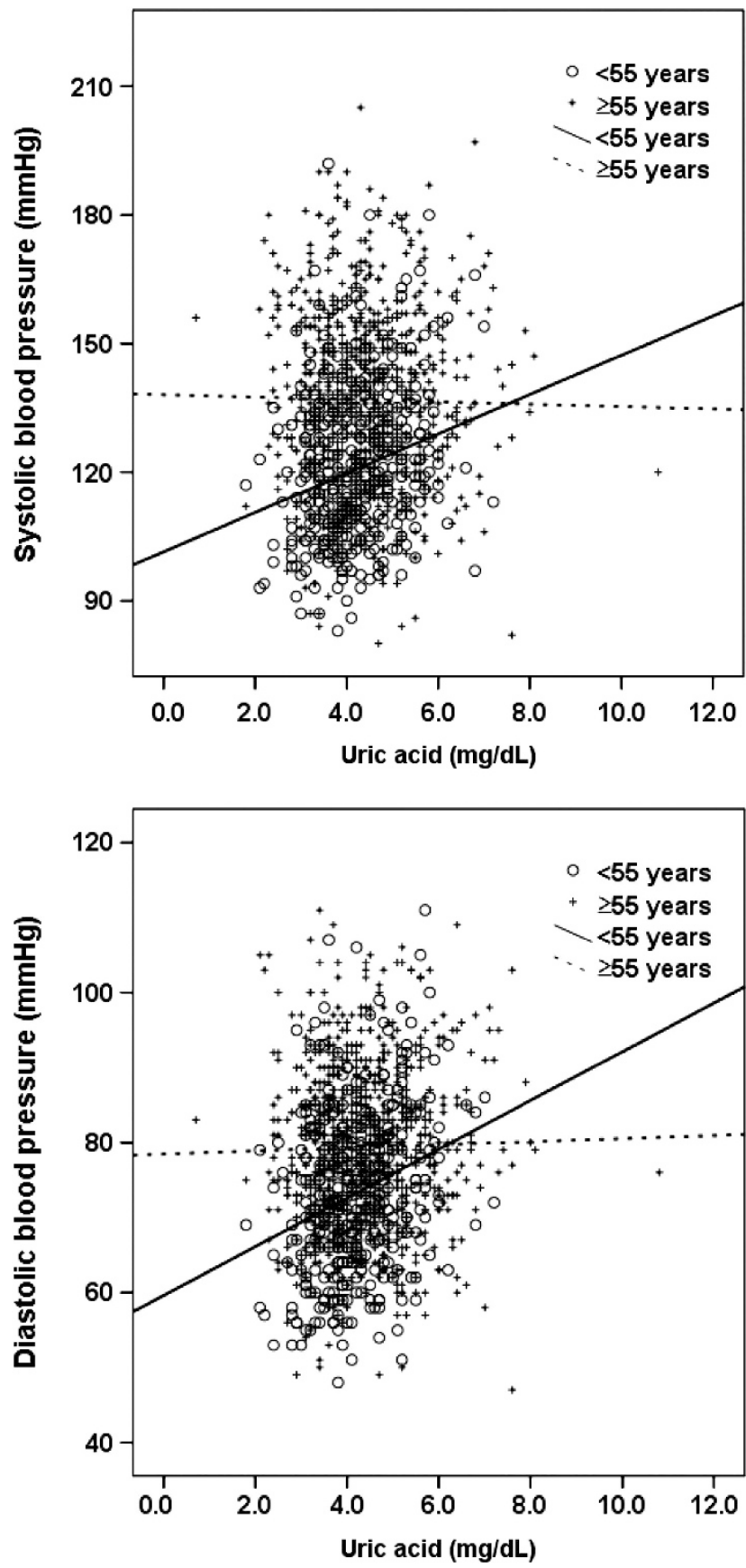

Figure 1 Correlation between serum uric acid (SUA) and blood pressure status of female participants categorized by age. In participants aged $<55$ years, SUA was significantly correlated with both systolic blood pressure (SBP; $r=0.236, P<0.001$ ) and diastolic blood pressure (DBP; $r=0.263$, $P<0.001)$ but not significantly correlated with SBP $(r=-0.014$, $P=0.684)$ and $\operatorname{DBP}(r=0.021, P=0.554)$ in those aged $\geqslant 55$ years. Analysis of covariance showed that the two regression lines in each graph were significantly different $(F=12.78, \quad P<0.001$ and $F=16.92$, $P<0.001$, respectively).

the analyses adjusted for age, gender, race/ethnicity and BMI percentile, the OR $(95 \% \mathrm{CI})$ of elevated $\mathrm{BP}$, which was defined as a SBP or DBP $\geqslant 95$ th percentile for age, sex and height, was 1.38 (1.16-1.65) for participants with SUA levels $\geqslant 5.5 \mathrm{mg} \mathrm{dl}^{-1}$ compared with $<5.5 \mathrm{mg} \mathrm{dl}^{-1} .{ }^{15}$ In 3329 participants in the Framingham Study (55.6\% women, age: $48.7 \pm 13.7$ years) who were free of hypertension, 
myocardial infarction, heart failure, renal failure or gout, each s.d. of SUA was associated with a multivariable-OR (95\% CI) of 1.17 (1.02-1.33) for developing hypertension and 1.11 (1.01-1.23) for BP progression. ${ }^{16}$ In the six-year follow-up of 3073 normotensive men (age: $35-57$ years) with baseline hyperuricemia (SUA $>7.0 \mathrm{mg} \mathrm{dl}^{-1}$ ) but without diabetes/glucose intolerance or metabolic syndrome from the Multiple Risk Factor Intervention Trial, normotensive men with baseline hyperuricemia had an $80 \%$ excess risk for incident hypertension (hazard ratio: 1.81; 95\% CI: 1.59-2.07) compared with those without baseline hyperuricemia. ${ }^{17}$ The magnitude of the risk, however, varied substantially because of the underlying heterogeneity in the study design, subject selection and the distribution of SUA. ${ }^{17}$ Despite these and similar findings in cross-sectional and longitudinal

Table 3 Interaction between age and serum uric acid on blood pressure status

\begin{tabular}{|c|c|c|}
\hline \multirow{3}{*}{$\begin{array}{l}\text { Characteristics } \\
N=1177 \\
\text { Age (years) }\end{array}$} & $S B P$ & $D B P$ \\
\hline & \multicolumn{2}{|c|}{$\beta$ (P-value) } \\
\hline & $1.078(<0.001)$ & $0.506(<0.001)$ \\
\hline Body mass index $\left(\mathrm{kg} \mathrm{m}^{-2}\right)$ & $1.248(<0.001)$ & $0.731(<0.001)$ \\
\hline Smoking status (\%) & $-3.096(0.340)$ & $-2.679(0.139)$ \\
\hline Drinking status (\%) & $-1.912(0.047)$ & $-0.288(0.592)$ \\
\hline History of CVD, $N(\%)$ & $2.166(0.402)$ & $0.450(0.755)$ \\
\hline Triglycerides $\left(\mathrm{mg} \mathrm{dl}^{-1}\right)$ & $17.98(<0.001)$ & $9.631(<0.001)$ \\
\hline $\mathrm{HDL}$ cholesterol (mg dl-1) & $0.171(<0.001)$ & $0.092(<0.001)$ \\
\hline LDL cholesterol (mgdl $\left.{ }^{-1}\right)$ & $-0.035(0.059)$ & $0.008(0.423)$ \\
\hline Lipid-lowering medication, \% & $0.052(0.983)$ & $-0.213(0.874)$ \\
\hline Fasting plasma glucose $\left(\mathrm{mgdl}^{-1}\right)$ & $36.19(<0.001)$ & $12.05(0.012)$ \\
\hline Antidiabetic medication, $N(\%)$ & $-9.359(0.005)$ & $-5.636(0.003)$ \\
\hline eGFR & $0.006(0.860)$ & $-0.018(0.360)$ \\
\hline Serum uric acid ( $\left.\mathrm{mg} \mathrm{dl}^{-1}\right)$ & $6.058(0.025)$ & $4.345(0.004)$ \\
\hline Age (years) $\times$ serum uric acid $\left(\mathrm{mg} \mathrm{dl}^{-1}\right)^{\mathrm{a}}$ & $-0.106(0.011)$ & $-0.070(0.003)$ \\
\hline$R^{2}$ & $0.278(<0.001)$ & $0.194(<0.001)$ \\
\hline
\end{tabular}

Abbreviations: CVD, cardiovascular disease; DBP, diastolic blood pressure; eGFR, estimated glomerular filtration rate; HDL, high-density lipoprotein; LDL, low-density lipoprotein; glomerular filtration rate; $\mathrm{HDL}$, high-density lipoprote
$\mathrm{SBP}$, systolic blood pressure; $\beta$, standard coefficient.

Data for triglycerides and fasting plasma glucose were skewed and log-transformed for analysis. aThe net effect of each interaction was estimated using a general linear model. studies, it was not clear whether the causative role of SUA can be inferred because of the possibility of the confounding factors (for example, age, drinking status, lipids, renal dysfunction, insulin resistance and diuretic use). As participants in these studies, as well as our study, were younger, the effect of hyperuricemia may be more pronounced in the younger subjects. ${ }^{17}$

The mechanisms that lead to elevated BP in individuals with hyperuricemia remains to be clarified. SUA reduces the levels of endothelial nitric oxide, which increases the blood flow to the skeletal muscles and enhances glucose uptake and is strongly associated with insulin action. ${ }^{18}$ SUA alters the proliferation/migration and nitric oxide release of human vascular cells, mediated by the expression of C-reactive protein, ${ }^{19}$ and it stimulates proliferation, angiotensin II production and oxidative stress in vascular smooth muscle cells through the tissue renin-angiotensin system. ${ }^{20}$ Thus, hyperuricemia induces endothelial dysfunction; this may provide insight into a pathogenic mechanism by which SUA may induce hypertension and vascular disease. ${ }^{21}$ We have previously demonstrated that SUA is also an independent determinant of insulin resistance, and combined assessment of SUA and high-sensitivity C-reactive protein levels provides incremental information for risk stratification of patients with metabolic syndrome in community-dwelling women. ${ }^{22}$ Recent studies suggest that SUA levels are lower in premenopausal than in postmenopausal women because estrogenic compounds enhance the renal urate clearance ${ }^{23}$ and are strongly associated with other cardiovascular risk factors such as age, gender, BMI, SBP, DBP, T-C, TG and FPG ${ }^{24,25}$ which have a causal role in the pathogenesis of CVD. In our study, the values of CVD risk factors in the younger participants aged $<55$ years were better than those in the older group (aged $\geqslant 55$ years), and the stronger association between SUA and BP among the younger group is consistent with previous cross-sectional studies. $^{26}$ A low prevalence of CVD risk factors, including renal dysfunction in younger participants, may explain the higher OR of increased SUA for hypertension in this group than among older participants. ${ }^{26}$ Additionally, young adolescents with new-onset essential hypertension often have increased SUA levels, ${ }^{27}$ and the strength of the relationship between SUA level and hypertension gradually decreases with increasing age and duration of hypertension, ${ }^{28}$ suggesting that SUA may be more important in

Table 4 Association between serum uric acid levels and blood pressure status of female participants categorized by age

\begin{tabular}{|c|c|c|c|c|c|c|c|}
\hline \multirow{2}{*}{$\begin{array}{l}\text { Characteristics } \\
\mathrm{N}=1177\end{array}$} & \multicolumn{3}{|c|}{ Age $<55$ years } & \multicolumn{3}{|c|}{ Age $\geqslant 55$ years } & \multirow[b]{2}{*}{ P-interaction } \\
\hline & $\mathrm{N}=351$ & OR $(95 \% C l)^{\mathrm{a}}$ & $\mathrm{P}$-value ${ }^{\mathrm{b}}$ & $N=826$ & OR $(95 \% C l)^{\mathrm{a}}$ & $\mathrm{P}$-value ${ }^{\mathrm{b}}$ & \\
\hline Prehypertension vs normotension & $118 / 180$ & & & $271 / 171$ & & & \\
\hline Tertile-1 (0.7-3.8 $\left.\mathrm{mg} \mathrm{dl}^{-1}\right)$ & $45 / 78$ & 1 (referent) & & $90 / 57$ & 1 (referent) & & 0.145 \\
\hline Tertile-2 (3.9-4.7 $\left.\mathrm{mg} \mathrm{dl}^{-1}\right)$ & $39 / 71$ & $0.94(0.53-1.68)$ & 0.840 & $91 / 56$ & $0.93(0.57-1.54)$ & 0.786 & \\
\hline Tertile-3 (4.8-10.8 mg dl-1) & $34 / 31$ & $1.48(0.75-2.89)$ & 0.256 & $90 / 58$ & $0.80(0.48-1.35)$ & 0.407 & \\
\hline Hypertension vs normotension & $53 / 180$ & & & $384 / 171$ & & & \\
\hline Tertile-1 (0.7-3.8 mg dl-1) & $13 / 78$ & 1 (referent) & & $126 / 57$ & 1 (referent) & & 0.009 \\
\hline Tertile-2 (3.9-4.7 mg dl-1) & $16 / 71$ & $1.44(0.56-3.68)$ & 0.451 & $137 / 56$ & $1.08(0.66-1.76)$ & 0.756 & \\
\hline Tertile-3 (4.8-10.8 $\mathrm{mg} \mathrm{dl}^{-1}$ ) & $24 / 31$ & $3.03(1.13-8.11)$ & 0.028 & $121 / 58$ & $0.75(0.45-1.24)$ & 0.263 & \\
\hline Hypertension vs prehypertension & $53 / 118$ & & & $384 / 271$ & & & \\
\hline Tertile-1 (0.7-3.8 $\left.\mathrm{mg} \mathrm{dl}^{-1}\right)$ & $13 / 45$ & 1 (referent) & & $126 / 90$ & 1 (referent) & & 0.133 \\
\hline Tertile-2 (3.9-4.7 $\left.\mathrm{mg} \mathrm{dl}^{-1}\right)$ & $16 / 39$ & $1.41(0.56-3.54)$ & 0.465 & $137 / 91$ & $1.02(0.69-1.52)$ & 0.909 & \\
\hline Tertile-3 (4.8-10.8 $\mathrm{mg} \mathrm{dl}^{-1}$ ) & $24 / 34$ & $1.96(0.79-4.86)$ & 0.144 & $121 / 90$ & $0.78(0.51-1.20)$ & 0.265 & \\
\hline
\end{tabular}

Abbreviations: $\mathrm{Cl}$, confidence interval; OR, odds ratio.

Data for triglycerides and fasting plasma glucose were skewed and log-transformed for analysis.

aMultivariate adjusted for age, obesity, drinking status, triglycerides, high-density lipoprotein cholesterol, fasting plasma glucose and antidiabetic medication, which were significant in Table 3.

b $P$-value versus Tertile-1. 
younger participants with earlier stages of hypertension. Experimental evidence has demonstrated that increased SUA elevates BP in a manner that is initially reversible but leads to an irreversible salt-sensitive hypertension over time, regardless of the SUA levels, ${ }^{29}$ and a randomized clinical trial has demonstrated that therapy that lowers SUA also lowers plasma renin activity and BP in this select population. ${ }^{27}$

Some limitations of this study must be considered. First, the crosssectional study design is limited in its ability to eliminate the causal relationships between age, SUA and BP. Second, SBP and DBP are based on a single assessment of $\mathrm{BP}$, which may introduce a misclassification bias. Third, we could not rule out one-time hypertension and white-coat hypertension. Fourth, formulas for eGFR tend to be less accurate in subjects with normal renal function than in those with chronic kidney disease, although ours is more accurate than that of serum creatinine ${ }^{30}$ or blood urea nitrogen because these parameters are not raised to outside the normal range until $60 \%$ of total kidney function is lost. Therefore, the demographics and referral source may limit generalizability.

In conclusion, this study showed that SUA levels were significantly associated with elevated BP in a middle aged-female population. The mechanism underlying this relationship is not clear and seems to be independent of traditional confounding factors, such as age, BMI, smoking status, drinking status, TG, HDL-C, LDL-C, use of lipidlowering and antidiabetic medication, FPG and eGFR. Further investigation of longitudinal data from our study will provide more definitive answers to this issue.

\section{CONFLICT OF INTEREST}

The authors declare no conflict of interest.

\section{ACKNOWLEDGEMENTS}

This work was supported, in part, by a grant-in-aid for Scientific Research from the Foundation for Development of Community (2012).

Author contributions: RK, YT and KK participated in the design of the study, performed the statistical analysis and drafted the manuscript. YT and TK contributed to the acquisition of data and its interpretation. MA contributed to the conception and design of the statistical analysis. TM conceived of the study, participated in its design, coordination and helped to draft the manuscript. All authors read and approved the manuscript.

1 Lewington S, Clarke R, Qizilbash N, Peto R, Collins R. Prospective Studies Collaboration: Age-specific relevance of usual blood pressure to vascular mortality: a metaanalysis of individual data for one million adults in 61 prospective studies. Lancet 2002; 360: 1903-1913.

2 Chobanian AV, Bakris GL, Black HR, Cushman WC, Green LA, Izzo Jr JL, Jones DW, Materson BJ, Oparil S, Wright Jr JT, Roccella EJ. Joint National Committee on Prevention, Detection, Evaluation, and Treatment of High Blood Pressure. National Heart, Lung, and Blood Institute; National High Blood Pressure Education Program Coordinating Committee. The seventh report of the Joint National Committee on Prevention, Detection, Evaluation, and Treatment of High Blood Pressure. Hypertension 2003; 42: 1206-1252.

3 Falkner B, Gidding SG, Portman R, Rosner B. Blood pressure variability and classification of prehypertension and hypertension in adolescence. Pediatrics 2008; 122: $238-242$.

4 Lyngdoh T, Marques-Vidal P, Paccaud F, Preisig M, Waeber G, Bochud M, Vollenweide $P$. Elevated serum uric acid is associated with high circulating inflammatory cytokines in the population-based Colaus study. PLoS One 2011; 6: e19901.

5 Zoccali C, Maio R, Mallamaci F, Sesti G, Perticone F. Uric acid and endothelial dysfunction in essential hypertension. J Am Soc Nephrol 2006; 17 1466-1471.
6 Mellen PB, Bleyer AJ, Erlinger TP, Evans GW, Nieto FJ, Wagenknecht LE, Wofford MR, Herrington DM. Serum uric acid predicts incident hypertension in a bi-ethnic cohort: the atherosclerosis risk in communities study. Hypertension 2006; 48 : 1037-4102.

7 Fang J, Alderman MH. Serum uric acid and cardiovascular mortality the NHANES I epidemiologic follow-up study, 1971-1992. National Health and Nutrition Examination Survey. JAMA 2000; 283: 2404-2410.

8 Meisinger C, Koenig W, Baumert J, Döring A. Uric acid levels are associated with allcause and cardiovascular disease mortality independent of systemic inflammation in men from the general population: the MONICA/KORA cohort study. Arterioscler Thromb Vasc Biol 2008; 28: 1186-1192.

9 Forman JP, Choi H, Curhan GC. Plasma uric acid level and risk for incident hypertension among men. J Am Soc Nephrol 2007; 18: 287-292.

10 Takayama S, Kawamoto R, Kusunoki T, Abe M, Onji M. Uric acid is an independent risk factor for carotid atherosclerosis in a Japanese elderly population without metabolic syndrome. Cardiovasc Diabetol 2012; 11: 2.

11 Friedewald WT, Levy RI, Fredrickson DS. Estimation of the concentration of low-density lipoprotein cholesterol in plasma, without use of the preparative ultracentrifuge. Clin Chem 1972; 18: 499-502.

12 Imai E, Horio M, Watanabe T, Iseki K, Yamagata K, Hara S, Ura N, Kiyohara Y, Moriyama T, Ando Y, Fujimoto S, Konta T, Yokoyama H, Makino H. Hishida A, Matsuo S. Prevalence of chronic kidney disease in the Japanese general population. Clin Exp Nephrol 2009; 13: 621-630.

13 Amagai Y, Ishikawa S, Gotoh T, Kayaba K, Nakamura Y, Kajii E. Age at menopause and mortality in Japan: the Jichi Medical School Cohort Study. J Epidemiol 2006; 16 $161-166$.

14 Shankar A, Klein R, Klein BE, Nieto FJ. The association between serum uric acid leve and long-term incidence of hypertension: population-based cohort study. J Hum Hypertens 2006; 20: 937-945

15 Loeffler LF, Navas-Acien A, Brady TM, Miller 3rd ER, Fadrowski JJ. Uric acid level and elevated blood pressure in US adolescents: National Health and Nutrition Examination Survey, 1999-2006. Hypertension 2012; 59: 811-817.

16 Sundström J, Sullivan L, D'Agostino RB, Levy D, Kannel WB, Vasan RS. Relations of serum uric acid to longitudinal blood pressure tracking and hypertension incidence. Hypertension 2005; 45: 28-33.

17 Krishnan E, Kwoh CK, Schumacher HR, Kuller L. Hyperuricemia and incidence of hypertension among men without metabolic syndrome. Hypertension 2007; 49 298-303.

18 Nakagawa T, Tuttle KR, Short RA, Johnson RJ. Hypothesis: fructose-induced hyperuricemia as a causal mechanism for the epidemic of the metabolic syndrome. Nat Clin Pract Nephrol 2005; 1: 80-86.

19 Kang DH, Park SK, Lee IK, Johnson RJ. Uric acid-induced C-reactive protein expression: implication on cell proliferation and nitric oxide production of human vascular cells. J Am Soc Nephrol 2005; 16: 3553-3562.

20 Corry DB, Eslami P, Yamamoto K, Nyby MD, Makino H, Tuck ML. Uric acid stimulate vascular smooth muscle cell proliferation and oxidative stress via the vascular renin-angiotensin system. J Hypertens 2008; 26: 269-275.

21 Khosla UM, Zharikov S, Finch JL, Nakagawa T, Roncal C, Mu W, Krotova K, Block ER, Prabhakar S, Johnson RJ. Hyperuricemia induces endothelial dysfunction. Kidney Int 2005; 67: 1739-1742.

22 Kawamoto R, Tabara Y, Kohara K, Miki T, Kusunoki T, Takayama S, Abe M, Katoh T, Ohtsuka N. Usefulness of combining serum uric acid and high-sensitivity C-reactive protein for risk stratification of patients with metabolic syndrome in community-dwelling women. Endocrine 2012; 43: (in press).

23 Stöckl D, Döring A, Thorand B, Heier M, Belcredi P, Meisinger C. Reproductive factors and serum uric acid levels in females from the general population: the KORA F4 study. PLoS One 2012; 7: e32668.

24 Lee J, Sparrow D, Vokonas PS, Landsberg L, Weiss ST. Uric acid and coronary heart disease risk: evidence for a role of uric acid in the obesity-insulin resistance syndrome. The Normative Aging Study. Am J Epidemiol 1995; 142: 288-294.

25 Chu NF, Wang DJ, Liou SH, Shieh SM. Relationship between hyperuricemia and other cardiovascular disease risk factors among adult males in Taiwan. Eur J Epidemio 2000; 16: 13-17

26 Grayson PC, Kim SY, LaValley M, Choi HK. Hyperuricemia and incident hypertension: a systematic review and meta-analysis. Arthritis Care Res 2011; 63: 102-110.

27 Feig DI, Soletsky B, Johnson RJ. Effect of allopurinol on blood pressure of adolescents with newly diagnosed essential hypertension: a randomized trial. JAMA 2008; 300: 924-932.

28 Brand FN, McGee DL, Kannel WB, Stokes 3rd J, Castelli WP. Hyperuricemia as a risk factor of coronary heart disease: the Framingham Study. Am J Epidemiol 1985; 121 $11-18$.

29 Watanabe S, Kang DH, Feng L, Nakagawa T, Kanellis J, Lan H, Mazzali M, Johnson RJ. Uric acid, hominoid evolution, and the pathogenesis of salt-sensitivity. Hypertension 2002; 40: 355-360.

30 Levey AS, Coresh J, Greene T, Stevens LA, Zhang YL, Hendriksen S, Kusek JW, Van Lente FChronic Kidney Disease Epidemiology Collaboration. Using standardized serum creatinine values in the modification of diet in renal disease study equation for estimating glomerular filtration rate. Ann Intern Med 2006; 145: 247-254. 